\title{
COLLABORATIVE SUPPLY MODEL AND CASE SIMULATION IN A TWO-LEVEL ASSEMBLE-TO-ORDER SYSTEM IN THE CONTEXT OF GLOBAL PURCHASING
}

\author{
Li, Q. Z. ${ }^{* * *}$; Fan, X. W. ${ }^{* *} ;$ Huang, W. J. ${ }^{* * * \#} \&$ Kwangseek, C. ${ }^{* * * *}$ \\ "National Academy of Economic Strategy, CASS, No. 28, Shuguang Xili, Beijing, P. R. China \\ ${ }^{* *}$ School of Logistics and E-Commerce, Zhejiang Wanli University, No. 8, Qianhu Road, Ningbo, \\ P. R. China \\ *** Business School, Zhejiang Wanli University, No. 8, Qianhu Road, Ningbo, P. R. China \\ School of Business and Economics, State University of New York at Plattsburgh, Plattsburgh, \\ NY12901, U.S.A. \\ E-Mail: huangwenjun001@email.zwu.edu.cn ( ${ }^{\#}$ Corresponding author)
}

\begin{abstract}
The lack of collaboration between overseas and local suppliers in global purchasing is a major challenge in assemble-to-order (ATO) supply chain management. This study established a collaborative supply chain model with a single manufacturer and multiple suppliers to explore the collaborative supply strategy in a time-price-sensitive ATO system. The method adopted the costbenefit analysis with time constraints. The profit functions of the manufacturer and local suppliers were given in decentralized decision mode, and the Nash equilibrium solution of supply chain decision was obtained. The strategy combination of collaborative supply was then determined. Herman Miller (Ningbo), Inc. was taken as an example, and a numerical simulation was discussed to illustrate the proposed approach. Different scenarios of the delivery time of overseas suppliers and the time sensitivity coefficient of customers were considered. Results confirm that supply collaboration has a significant impact on the ATO supply chain performance in global purchasing. The collaborative supply strategy combination determined by model optimization can improve the expected profits of the manufacturer and local suppliers. The conclusion of this study can provide a theoretical basis and a decision-making reference for supply chain enterprises to develop effective global purchasing strategies in time-price-sensitive markets.

(Received in February 2017, accepted in May 2017. This paper was with the authors 1 month for 2 revisions.)
\end{abstract}

Key Words: Assemble-to-Order (ATO), Global Purchasing, Collaborative Supply, Case Simulation

\section{INTRODUCTION}

In the new economy, an increasing number of consumers favor customized production and are not only concerned with price but also sensitive to delivery time [1]. Assemble-to-order (ATO) then gradually becomes a postponement manufacturing mode widely used by multinational manufacturers, such as Dell, Toyota, and the major automobile manufacturers in the United States [2, 3]. In the ATO mode, the assembly enterprises preorder various standard components and then assemble them into final products after receiving customer orders. This mode improves the promptness of customer's response and promotes easy fulfillment of their diversified needs [4].

Assembly centers have been transferred to developing countries. Multinational manufacturers have tried to nurture and develop local suppliers around assembly centers to reduce purchasing costs and to implement the localized purchasing strategy of auxiliary accessories while maintaining purchasing core components overseas (mainly from the home country). Numerous local auxiliary accessory suppliers with stable delivery time and a few overseas core component suppliers with high delivery time uncertainty constitute a new supply structure of a multinational ATO system, which greatly increases the complexity of 
supply chain. The assembly enterprises must collaboratively optimize the supply system to address the contradiction between controlling production costs and providing quick responses to customer needs. The achievement of collaborative supply between overseas and local suppliers becomes the main problem in the operation of the ATO supply chain.

Recent studies have paid considerable attention to the collaboration issues in the ATO system based on time modeling [5-7]. However, most of them have focused on the vertical collaboration between suppliers and manufacturers, and only a few have focused on the horizontal collaboration among suppliers. They have mainly assumed that the delivery time of different suppliers follows the same distribution function. However, this assumption is not in line with the state of the ATO system in global purchasing. This study accordingly takes the significant differences in delivery time between local and overseas suppliers as a precondition and aims to find the optimal collaborative supply strategy in the time-price-sensitive ATO supply chain.

\section{STATE OF THE ART}

The early research on the ATO system mainly focused on obtaining the optimal production and inventory strategies of manufacturers. Gallien and Wein considered a two-level assembly system in which the demand followed the Poisson distribution and the delivery time of suppliers followed the same distribution but was independent. They obtained the optimal solution when using the $(Q, r)$ strategy under the condition of the minimum inventory cost [8]. Fong et al. found the optimal ordering strategy in the ATO system with the deterministic demand and random delivery time [9]. Benjaafar and ElHafsi studied the optimal production and storage strategy in an ATO system with multiple components and single product under the assumptions that customer demands followed an independent Poisson distribution and that shortage cost existed [10]. Such literature has mainly focused on the demand side in the ATO system and studied the ways of adjusting the component inventory strategy to deal with the changes in market demands. With the popularity of global purchasing in multinational assembly enterprises, the uncertainty on the component supply side gradually attracts the attention of researchers [5].

First, the collaboration issues under uncertain delivery quantity are of concern. The uncertainty in the delivery quantity of suppliers mainly results from the uncertainties in their production and supply capacity. Gurnani and Gerchak discussed about the optimal decision of suppliers and the manufacturer in an assembly system with two suppliers and one manufacturer under random supply based on shortage and additional penalty costs [11]. Maddah and Jaber studied the decision problem of economic order quantity with uncertain supply [12]. Güler and Bilgiç analysed the ways of establishing penalty and incentive mechanisms to achieve supply chain collaboration under uncertain supply and demand in a two-level ATO system [13]. Feng et al. used a game theory approach to determine the component price and inventory in a two-level ATO system with two suppliers and one manufacturer [14]. Li and Ma established a decision model based on overflow inventory penalty and proposed a supply chain collaboration strategy based on risk sharing [15]. Such literature has mainly studied the influence of the delivery quantity uncertainty on the ATO system collaboration and tried to collaborate suppliers by introducing a penalty mechanism or an incentive mechanism, thereby ensuring the stability of the delivery quantity of suppliers. Research has regarded delivery time as a deterministic factor, which simplifies the research conditions and the process of finding the collaborative mechanism of supply chain. However, neglecting the time variable limits the practical value of research conclusions.

Second, many researchers have begun to study the collaboration under uncertain delivery time, considering that the importance of time-based competition has become increasingly 
prominent. Chandra discussed the interaction between suppliers and buyers under unstable delivery time and believed that short delivery time led to high supplier quotation, thereby realizing the cost transfer [6]. Wang constructed an inventory decision model to achieve the vertical collaboration between a supplier and a manufacturer in a two-level supply chain with a single manufacturer and a single retailer [7]. Song and Yang analysed the optimization and collaboration problem in perishable supply chain from the perspective of random delivery time [16]. Dan and Li introduced delivery-time-sensitive and price-sensitive factors to study the hybrid replenishment strategy of an ATO manufacturer and the production strategy of component suppliers under just in time (JIT) and offered the corresponding algorithm [17]. However, these studies have focused mostly on the vertical collaboration problem between a single supplier and a single manufacturer in the supply chain and rarely on the horizontal collaboration of a complex supply chain, including multiple peer suppliers.

In global purchasing, the supply chain system of multinational assembly enterprises is an at least two-level ATO system composed of customers, assembly enterprises, and suppliers. In this system, whether the local and overseas suppliers could supply collaboratively directly affects the production schedule and inventory costs of manufacturers. Multinational assembly enterprises must effectively deal with the differences in delivery time characteristics between the two types of suppliers to achieve horizontal collaboration. $\mathrm{Li}$ and $\mathrm{Ma}$ established a collaborative supply model with two suppliers and one manufacturer under uncertain delivery time and compared the differences between supply chain profit and optimal solution in two decision modes by case analysis, including without and with considering collaborative supply. The results verified that the supply chain profit that considers collaborative supply decision was significantly greater than the supply chain profit that does not [15]. Moreover, the delivery time was considerably less for the supply chain profit that considers collaborative supply decision [15]. The importance of the horizontal collaboration among suppliers was highlighted. Nevertheless, this discourse assumed that the delivery time of two suppliers followed the same distribution function. In fact, significant differences in delivery time exist between numerous local auxiliary accessory suppliers with stable delivery time and a few overseas core component suppliers with high delivery time uncertainty. Therefore, this study considers a two-level ATO supply chain system with two suppliers and a single manufacturer. A collaborative supply model is established based on the significant differences in the delivery time of the two suppliers to explore the optimal cooperation strategy in global purchasing by model optimization and case simulation.

The rest of this study is organized as follows. Section 3 introduces the delivery time factor into cost-benefit analysis (CBA). The supply decision models of the manufacturer and suppliers are built, and the functional relationships among supply chain profit, product price, component-purchasing price, and delivery time are established. The critical conditions of the optimal supply chain profit are obtained through model optimization. Section 4 presents the numerical analysis and scenario simulation with Herman Miller (Ningbo), Inc. as an example. Finally, Section 5 concludes this study.

\section{METHODOLOGY}

\subsection{Problem descriptions and assumptions}

A two-level ATO supply chain system that is composed of two suppliers (local and overseas suppliers) and a single manufacturer (assembly enterprise) is considered, in which the manufacturer occupies the core status. The manufacturer determines the order quantity and order time of components. The suppliers determine the production time and adopt the JIT delivery mode. We assume that the final product is composed of only two components, which are supplied by the two suppliers at a ratio of 1:1 independently, to simplify the model, as 
shown in Fig. 1. The delivery time of the local supplier follows the probability distribution function $F(x)$ and probability density $f(x)$, and the delivery time of the overseas supplier follows the probability distribution function $G(y)$ and probability density $g(y)$.

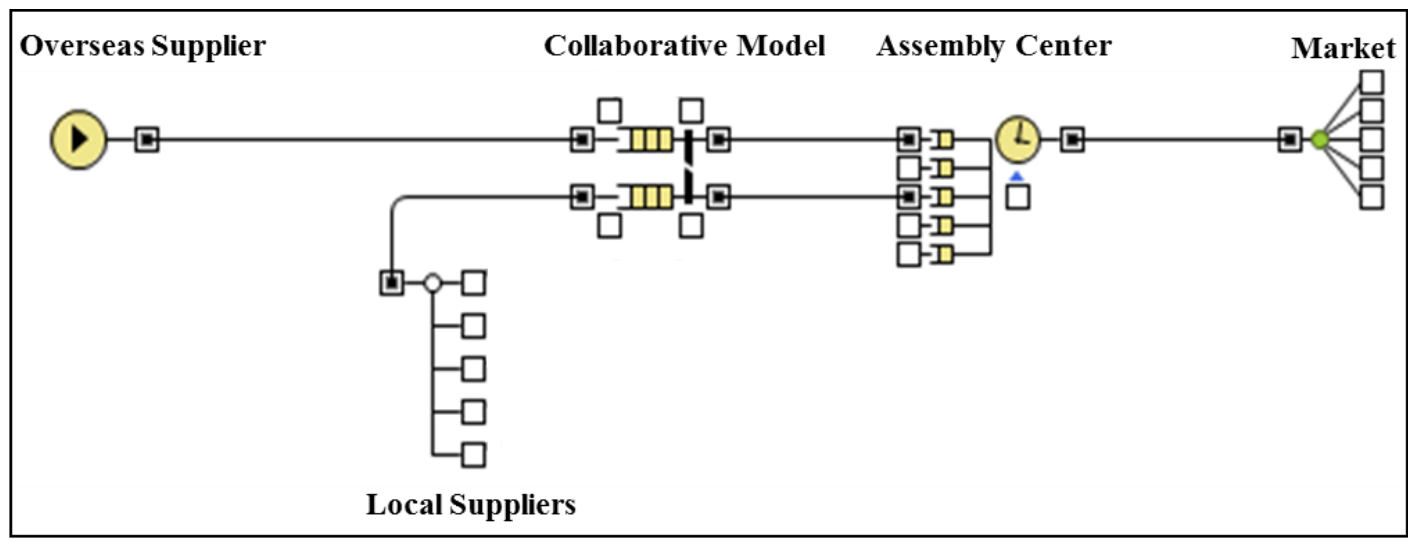

Figure 1: Concept model of collaborative principle in an ATO supply chain system.

In the decentralized decision-making mode, for a specific product provided by supply chain, the manufacturer, as the core enterprise, initially determines the final delivery time $T$ and product price $P$ according to the customer demand $Q$ and then places orders to the local and overseas suppliers. The suppliers organize production according to the orders and supply to the manufacturer at delivery time $T_{1}, T_{2}$ and purchasing price $P_{1}, P_{2}$ in the contract. Finally, the manufacturer assembles and submits to customers at price $P$. The delivery time $T$ of the manufacturer is determined by the latest delivery time and assembly and the transportation time $T_{m}$ (not considered here) of the two suppliers, as shown in Fig. 2. The previous literature has indicated that long response time leads to high price and low demands [18]. Therefore, customer demands are defined as follows:

$$
Q=\rho-a P-v T
$$

where $\rho$ is the maximum market demands of unit time, $a$ is the customer sensitivity coefficient to price, and $v$ is the sensitivity coefficient to delivery time. $P$ is the product price, and $T$ is the delivery time.

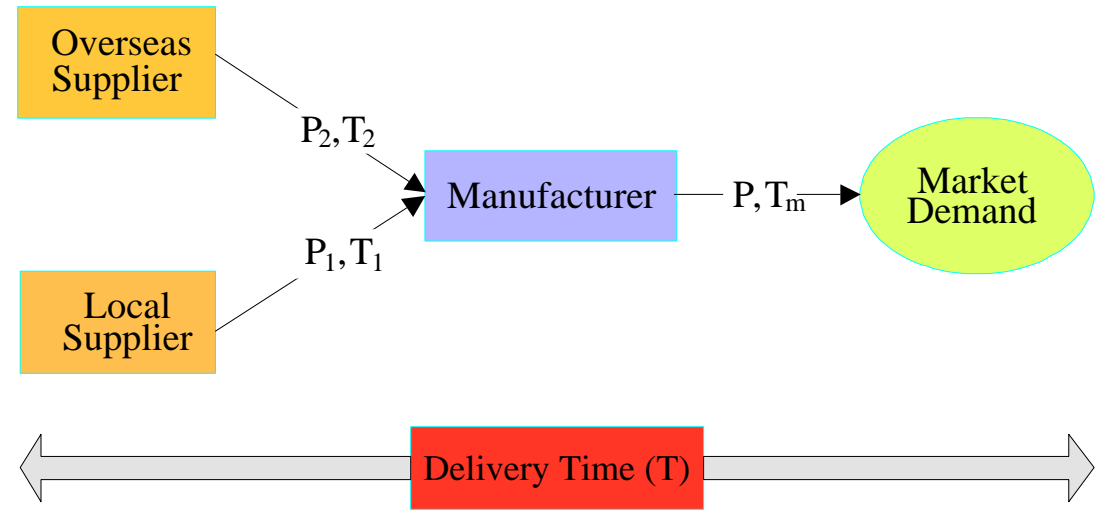

Figure 2: Simplified diagram of an ATO supply chain system.

The actual delivery time $t_{1}$ of the local supplier is a random variable. According to Literature [18], $t_{1}$ follows asymptotic exponential distribution with parameter $\theta_{1}$. The data fitting of the delivery time of Herman Miller, Inc. (see Fig. 4) and the previous study validate that the actual delivery time $t_{2}$ of the overseas supplier follows normal distribution [19]. Therefore, the probability density functions of the two suppliers are respectively defined as follows: 


$$
\begin{aligned}
& f\left(t_{1}\right)=\left\{\begin{array}{lr}
\theta_{1} e^{-\theta_{1} t_{1}} & \left(t_{1} \succ 0\right) \\
0 & \text { others }
\end{array} \quad\left(\theta_{1} \succ 0\right)\right. \\
& g\left(t_{2}\right)= \begin{cases}\frac{1}{\sqrt{2 \pi} \sigma} e^{-\frac{\left(t_{2}-\mu\right)^{2}}{2 \sigma^{2}}} & \left(t_{2} \succ 0\right) \\
0 & \text { others }\end{cases}
\end{aligned}
$$

The delivery process of the overseas supplier is highly complex, because of long-distance transportation, customs clearance, and other uncertain factors, are difficult to tackle. By contrast, the delivery process of the local supplier has considerable spaces to be optimized because of commonly having the characteristics of small size, strong decision flexibility, and short transport distance. Therefore, this study takes the delivery time of the overseas supplier as a constraint and determines the ways of adjusting the cooperation strategy with the local supplier to achieve collaborative supply to improve the response capability and the customer service level of the supply chain. The manufacturer considers the uncertain delivery time of the overseas supplier in setting the optimal product price and the purchasing strategy to the local supplier based on the maximization of its own benefits. The local supplier arranges production according to the requirements of the manufacturer and strives to achieve the JIT supply. The profit decision models of the two suppliers and one manufacturer are established based on the aforementioned situation.

Assumptions:

(1) In this model, the manufacturer is the leader of the supply chain and sets the component-purchasing price, delivery time, and order quantity based on the maximization of its own benefits. The suppliers are the executive party of the purchasing strategy.

(2) No information sharing occurs between the two suppliers.

(3) The local supplier is not allowed to supply in advance.

The distribution function of the actual delivery time of the local supplier is as follows:

$$
F\left(t_{1}\right)=1-e^{-\theta_{t_{1}}} \quad\left(\theta_{1} \succ 0\right)
$$

where $1 / \theta_{1}$ indicates the average delivery time when the local supplier finishes an order.

Parameters:

$P$ : Price of the final product; $Q$ : Demand of customer; $T$ : Contract delivery time of manufacturer; $P_{1}$ : Contract purchasing price from local supplier; $P_{2}$ : Contract purchasing price from overseas supplier; $T_{1}$ : Contract delivery time of local supplier; $T_{2}$ : Contract delivery time of overseas supplier; $T_{m}$ : Assembly and transportation time (not considered in this study); $t_{1}$ : Actual delivery time of local supplier, $F\left(t_{1}\right)$ is its probability distribution function, and $f\left(t_{1}\right)$ is the probability density function; $t_{2}$ : Actual delivery time of overseas supplier, $G\left(t_{1}\right)$ is its probability distribution function, and $g\left(t_{1}\right)$ is the probability density function; $\rho$ : Maximum market demands of unit time; $a$ : Customer sensitivity coefficient to price; $v$ : Sensitivity coefficient to delivery time; $h_{1}$ : Unit inventory cost of local supplier; $h_{2}$ : Unit inventory cost of manufacturer; $C_{1}$ : Unit production cost of local supplier; $C_{m}$ : Unit assembly cost of manufacturer; $\beta$ : Deferred delivery penalty cost of local supplier; $\Pi_{m}$ : Expected profit of manufacturer; $\Pi_{s}$ : Expected profit of local supplier.

\subsection{Model formulation}

In the ATO production mode, the local supplier keeps inventory, and the unit product cost of the local supplier mainly includes production cost, inventory cost, and penalty cost. Therefore, the expected profit function of the local supplier is expressed as follows: 


$$
\Pi_{s}=\left[P_{1}-C_{1}-h_{1} \int_{0}^{T_{1}}\left(T_{1}-t_{1}\right) f\left(t_{1}\right) d t_{1}-\beta \int_{T_{1}}^{\infty}\left(t_{1}-T_{1}\right) f\left(t_{1}\right) d t_{1}\right] Q
$$

where the decision variables of the local supplier are $P_{1}$ and $T_{1}$, the third item of Eq. (5) is the inventory cost incurred when the local supplier finishes production in advance, the fourth item is the penalty cost incurred when the delivery of the local supplier defers, and $Q$ is the demand.

The manufacturer cannot start assembling in the ATO mode until components from the two suppliers are available. The delayed arrival of any party of suppliers will lead to increases in the total inventory cost of the manufacturer. Therefore, the unit product cost of the manufacturer is composed of the inventory cost that resulted from the non-collaboration of the two suppliers, production cost, and purchasing cost. The expected profit function of the manufacturer is, thus, expressed as follows:

$$
\Pi_{m}=\left[P-P_{1}-P_{2}-C_{m}-h_{2} \int_{T_{1}}^{\infty} \int_{0}^{\infty}\left|\left(t_{1}-T_{1}\right)-\left(t_{2}-T_{2}\right)\right| f\left(t_{1}\right) g\left(t_{2}\right) d t_{1} d t_{2}+\beta \int_{T_{1}}^{\infty}\left(t_{1}-T_{1}\right) f\left(t_{1}\right) d t_{1}\right] Q
$$

where the decision variables of the manufacturer are $P, T_{1}$ and $Q$, the fifth item of Eq. (6) is the inventory cost of the manufacturer that resulted from the non-collaborative supply of the two suppliers, and the sixth item is the penalty income from the supplier because of deferred delivery.

\subsection{Optimal solutions}

Under the conditions that the overseas and local suppliers supply independently and that the delivery time of the overseas supplier is uncertain, the manufacturer sets the optimal productselling price as well as the component-purchasing price, delivery time, and delivery quantity of the local supplier based on the maximization of its own benefits.

The best choice of the manufacturer for selling price $P$ and order quantity $Q$ is first studied under the given component-purchasing price and order quantity.

Proposition 1: For fixed component price $P_{1}, P_{2}$ and delivery time $T_{1}, T_{2}$, the profit function of the manufacturer is a concave function with respect to selling price $P$, and a unique $P$ exists to make the expected profit of the manufacturer maximum, that is,

$$
P^{*}=\frac{1}{2 a}\left[\rho-v T+a P_{1}+a P_{2}+a C_{m}+a h_{2} \int_{T_{1}}^{\infty} \int_{0}^{\infty}\left|\left(t_{1}-T_{1}\right)-\left(t_{2}-T_{2}\right)\right| f\left(t_{1}\right) g\left(t_{2}\right) d t_{1} d t_{2}-a \beta \int_{T_{1}}^{\infty}\left(t_{1}-T_{1}\right) f\left(t_{1}\right) d t_{1}\right]
$$

The economic order quantity is as follows:

$$
Q^{*}=\frac{1}{2}\left[\rho-v T-a P_{1}-a P_{2}-a C_{m}-a h_{2} \int_{T_{1}}^{\infty} \int_{0}^{\infty}\left|\left(t_{1}-T_{1}\right)-\left(t_{2}-T_{2}\right)\right| f\left(t_{1}\right) g\left(t_{2}\right) d t_{1} d t_{2}+a \beta \int_{T_{1}}^{\infty}\left(t_{1}-T_{1}\right) f\left(t_{1}\right) d t_{1}\right]
$$

Proof of proposition 1: Eq. (1) is substituted by Eq. (6), and the first and second derivatives are taken with respect to $P$, that is,

$$
\begin{gathered}
\prod_{m}=\left[P-P_{1}-P_{2}-C_{m}-h_{2} \int_{T_{1}}^{\infty} \int_{0}^{\infty}\left|\left(t_{1}-T_{1}\right)-\left(t_{2}-T_{2}\right)\right| f\left(t_{1}\right) g\left(t_{2}\right) d t_{1} d t_{2}+\beta \int_{T_{1}}^{\infty}\left(t_{1}-T_{1}\right) f\left(t_{1}\right) d t_{1}\right][\rho-a P-v T], \\
\frac{\partial \prod_{m}}{\partial P}=\rho-v T-2 a P+a P_{1}+a P_{2}+a C_{m}+a h_{2} \int_{T_{1} 0}^{\infty} \int_{0}^{\infty}\left|\left(t_{1}-T_{1}\right)-\left(t_{2}-T_{2}\right)\right| f\left(t_{1}\right) g\left(t_{2}\right) d t_{1} d t_{2}-a \beta \int_{T_{1}}^{\infty}\left(t_{1}-T_{1}\right) f\left(t_{1}\right) d t_{1}, \\
\frac{\partial^{2} \prod_{m}}{\partial P^{2}}=-2 a \prec 0 .
\end{gathered}
$$

The second derivative is less than zero, which indicates that the profit of the manufacturer is a concave function with respect to product-selling price $P$; hence, proposition 1 is true. We then let the first derivative be zero, and Eq. (7) holds. Eq. (7) is substituted by Eq. (1), and Eq. (8) holds.

Practical implication: Under the established supply chain cooperation strategy, the manufacturer needs to price the product and determine the purchasing quantity accurately. The optimal pricing is closely related to the supply collaboration degree of the two suppliers. 
High supply collaboration degree results in strong price competitiveness.

The local supplier will then negotiate price with the manufacturer according to the order quantity and delivery time determined by the manufacturer to maximize its own profit.

Proposition 2: For fixed order quantity and delivery time, the profit function of the local supplier is a concave function with respect to component price $P_{1}$, and a unique component price $P_{1}$ is available to make the expected profit of the local supplier maximum, that is,

$$
\begin{aligned}
P_{1}^{*}= & \frac{1}{2 a}\left[\rho-v T-a P_{2}-a C_{m}+a C_{1}-a h_{2} \int_{T_{1}}^{\infty} \int_{0}^{\infty}\left|\left(t_{1}-T_{1}\right)-\left(t_{2}-T_{2}\right)\right| f\left(t_{1}\right) g\left(t_{2}\right) d t_{1} d t_{2}+\right. \\
& \left.a h_{1} \int_{0}^{T_{1}}\left(T_{1}-t_{1}\right) f\left(t_{1}\right) d t_{1}\right]+\beta \int_{T_{1}}^{\infty}\left(t_{1}-T_{1}\right) f\left(t_{1}\right) d t_{1}
\end{aligned}
$$

Proof of proposition 2: Eq. (8) is substituted by Eq. (5), and the first and second derivatives are taken with respect to $P_{1}$, that is,

$$
\begin{gathered}
\frac{\partial \prod_{s}}{\partial P_{1}}=-a P_{1}+\frac{1}{2}\left[\rho-v T-a P_{2}-a C_{m}+a C_{1}-a h_{2} \int_{T_{1}}^{\infty} \int_{0}^{\infty}\left(t_{1}-T_{1}\right)-\left(t_{2}-T_{2}\right) \mid f\left(t_{1}\right) g\left(t_{2}\right) d t_{1} d t_{2}+\right. \\
\left.a h_{1} \int_{0}^{T_{1}}\left(T_{1}-t_{1}\right) f\left(t_{1}\right) d t_{1}\right]+a \beta \int_{T_{1}}^{\infty}\left(t_{1}-T_{1}\right) f\left(t_{1}\right) d t_{1}, \\
\frac{\partial^{2} \prod_{s}}{\partial P_{1}^{2}}=-a \prec 0 .
\end{gathered}
$$

The second derivative with respect to $P_{1}$ of the profit function of the local supplier is less than zero, which indicates that the function is a concave function with respect to $P_{1}$; hence, proposition 2 is true. The first derivative is set as zero, and Eq. (9) holds.

Practical implication: The purchasing price $P_{1}$ is the main moderator in supply chain cooperation, and the manufacturer needs to accurately decide the purchasing price to ensure the reasonable profit of the local supplier. The optimal decision of the supplier can then be guided to meet the supply conditions set by the manufacturer.

The optimal delivery time $T_{1}$ of the local supplier is subsequently determined.

Proposition 3: For certain purchasing price and purchasing quantity, the profit function of the local supplier is a concave function with respect to delivery time $T_{1}$, and a unique optimal $T_{1}$ exists to make the expected profit of the local supplier maximum, that is,

$$
T_{1}^{*}=\frac{1}{\theta_{1}} \ln \left[\frac{a h_{2} \theta_{1} \int_{0}^{\infty}\left|t_{2}-T_{2}\right| g\left(t_{2}\right) d t_{2}}{v}\right]
$$

Proof of proposition 3: Eq. (9) is substituted by Eq. (5), and the first and second derivatives are taken with respect to $T_{1}$, that is,

$$
\begin{aligned}
& \frac{\partial \prod_{s}}{\partial T_{1}}=\frac{1}{2 a}\left[-v+a h_{2} \int_{0}^{\infty}\left|t_{2}-T_{2}\right| f\left(T_{1}\right) g\left(t_{2}\right) d t_{2}\right], \\
& \frac{\partial^{2} \prod_{s}}{\partial T_{1}^{2}}=-\frac{1}{2} h_{2} \theta_{1}^{2} e^{-\theta_{1} T_{1}} \int_{0}^{\infty}\left|t_{2}-T_{2}\right| g\left(t_{2}\right) d t_{2} \prec 0 .
\end{aligned}
$$

The second derivative with respect to $T_{1}$ of the profit function of the local supplier is less than zero, which implies that the profit function of the local supplier is a concave function with respect to $T_{1}$. Accordingly, proposition 3 is true. The density function of the delivery time of the local supplier is substituted by the first derivative. The first derivative is allowed to be zero, and Eq. (10) holds. 
Practical implication: When the manufacturer determines the delivery time of the local supplier, the delivery time sensitivity of the customer and the distribution characteristics of the delivery time of the overseas supplier should comprehensively be considered.

The Nash equilibrium solution $\left(P^{*}, P_{1}{ }^{*}, T_{1}{ }^{*}\right)$ of the supply chain can be obtained by combining Eqs. (7), (9), and (10), and the strategy combination $\left(T_{1}^{*}, T_{2}\right)$ is the strategy combination of collaborative supply. The manufacturer, as the leading party, guides the optimal decision of the suppliers to meet the supply conditions set by the manufacturer through pricing the product precisely and optimizing the cooperation strategy with the local supplier to maximize its own benefits.

\section{RESULT ANALYSIS AND DISCUSSION}

\subsection{Parameter setting}

The main parameters in this study are from Herman Miller (Ningbo), Inc. Herman Miller is headquartered in the United States and is the second largest office furniture manufacturer in the world. The company produces seats, cabinets, and office appendages. These products are assembled according to the individual needs of customers. Herman Miller has three overseas assembly centers in the United Kingdom, China, and India. The core components are from the headquarters in the United States, and the auxiliary accessories are purchased from local suppliers. The delivery time of overseas supplier is highly uncertain. Therefore, the selection of an effective cooperation strategy to achieve collaborative supply between auxiliary accessories and core components to promote production responsiveness and eliminate excess inventory is the main problem that each assembly center faces.

Herman Miller (Ningbo), Inc. is the assembly center in the Asia-Pacific region. This study collects the production, inventory, and supply data related to the Aeron chair of Herman Miller (Ningbo), Inc. The unit inventory cost of the local supplier $h_{1}=\$ 6 /$ day, the unit inventory cost of the manufacturer $h_{2}=\$ 10 /$ day, and the penalty cost of the local supplier for the deferred delivery of unit product $\beta=\$ 15 /$ day. The market demand $\rho=1600$ pieces/week, $a=2$ pieces $\$$, and $v=10$ pieces $/$ day. The other parameters are $C_{m}=\$ 25 /$ piece and $C_{1}=$ $\$ 48 /$ piece. The historical data of the delivery time of suppliers show that the average delivery time of the local supplier is eight days (that is, $\theta_{1}=1 / 8$ ). The data fitting by using Minitab presents that the delivery time of the overseas supplier follows the normal distribution of $N\left(56,13.89^{2}\right.$ ) (Fig. 3). The $P$ value is greater than 0.05 by testing (Fig. 4), and the fitting result of this set of data following normal distribution is, thus, credible.

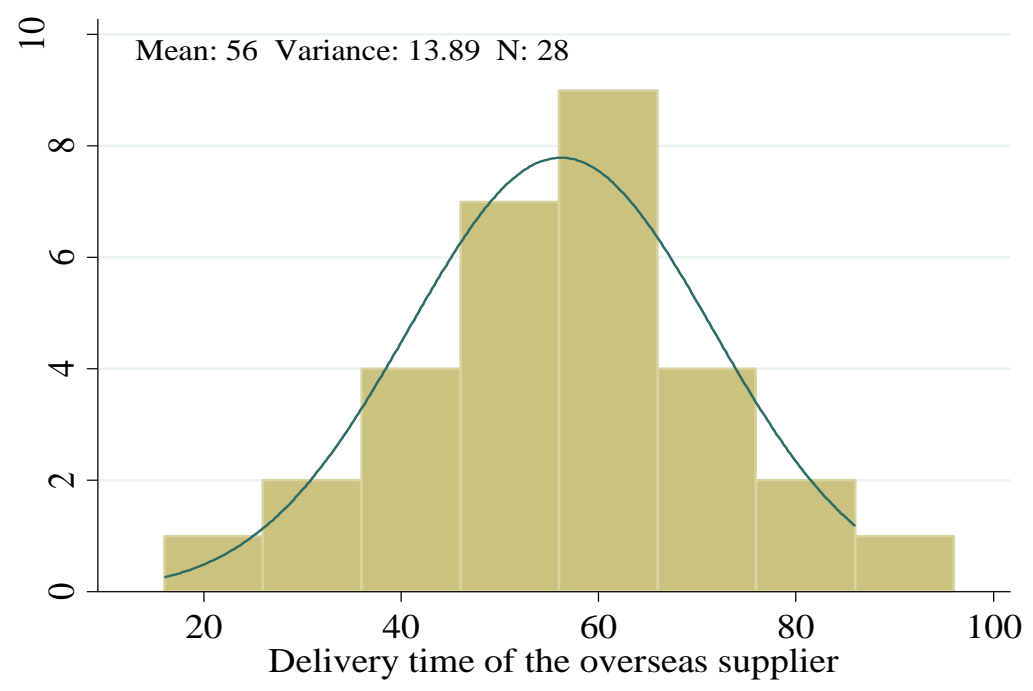

Figure 3: Distribution profile of the delivery time function of the overseas supplier. 
The optimal product price $P^{*}$ is calculated by Eq. (7), and the optimal purchasing price from the local supplier $P_{1}{ }^{*}$ and the corresponding purchasing quantity $Q^{*}$ are respectively calculated by Eqs. (9) and (8), the optimal delivery time $T_{1}{ }^{*}$ is calculated by Eq. (10), and the expected profits $\Pi_{s}^{*}, \Pi_{m}^{*}$ under the optimal decision are respectively calculated by Eqs. (5) and (6). The delivery time of the overseas supplier and the delivery time sensitivity of the customer are the two important premises of supply chain optimization decision. This study uses Mathcad for the numerical simulation analysis of the supply chain optimization decision from the scenarios of extension of the delivery time of the overseas supplier and the different delivery time sensitivities of customers based on the abovementioned calculation process.

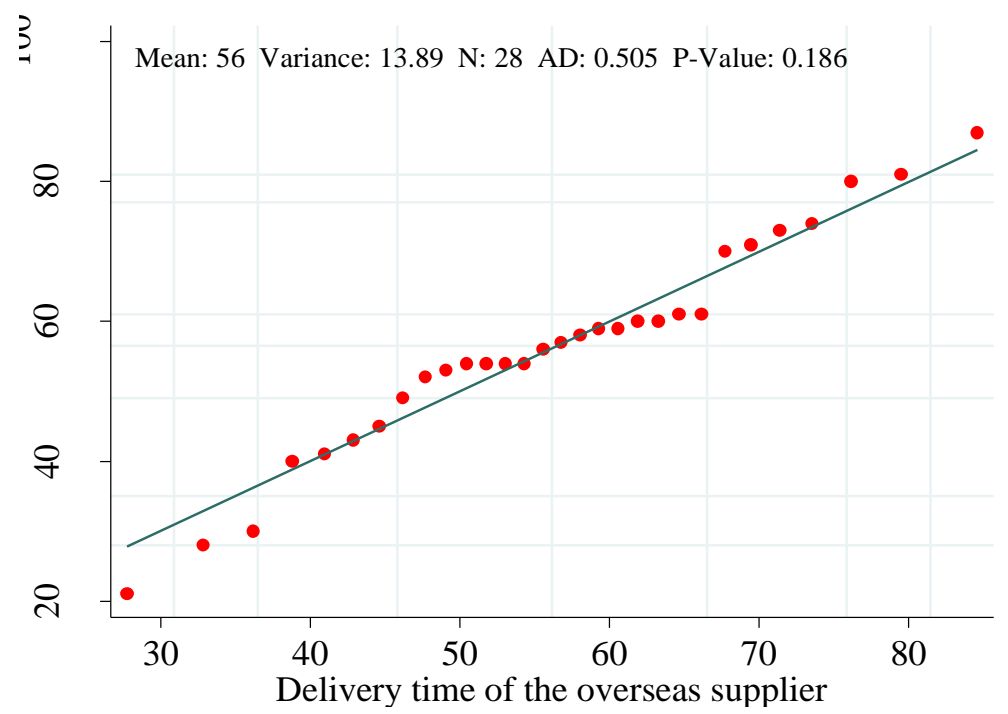

Figure 4: Normal distribution test of the delivery time of the overseas supplier.

\subsection{Effect of the extension of the delivery time $\left(T_{2}\right)$ of overseas supplier on supply chain decision results}

This section only considers the effect of the extension of the delivery time of the overseas supplier. The simulation interval of $T_{2}$ is set to 40-90 days according to the distribution characteristics of the delivery time of the overseas supplier. The results in Table I can be derived by substituting the parameters with the model.

We can draw the changing trends of the supply chain decision results under different delivery times of the overseas supplier according to the data in Table I, as shown in Fig. 5.

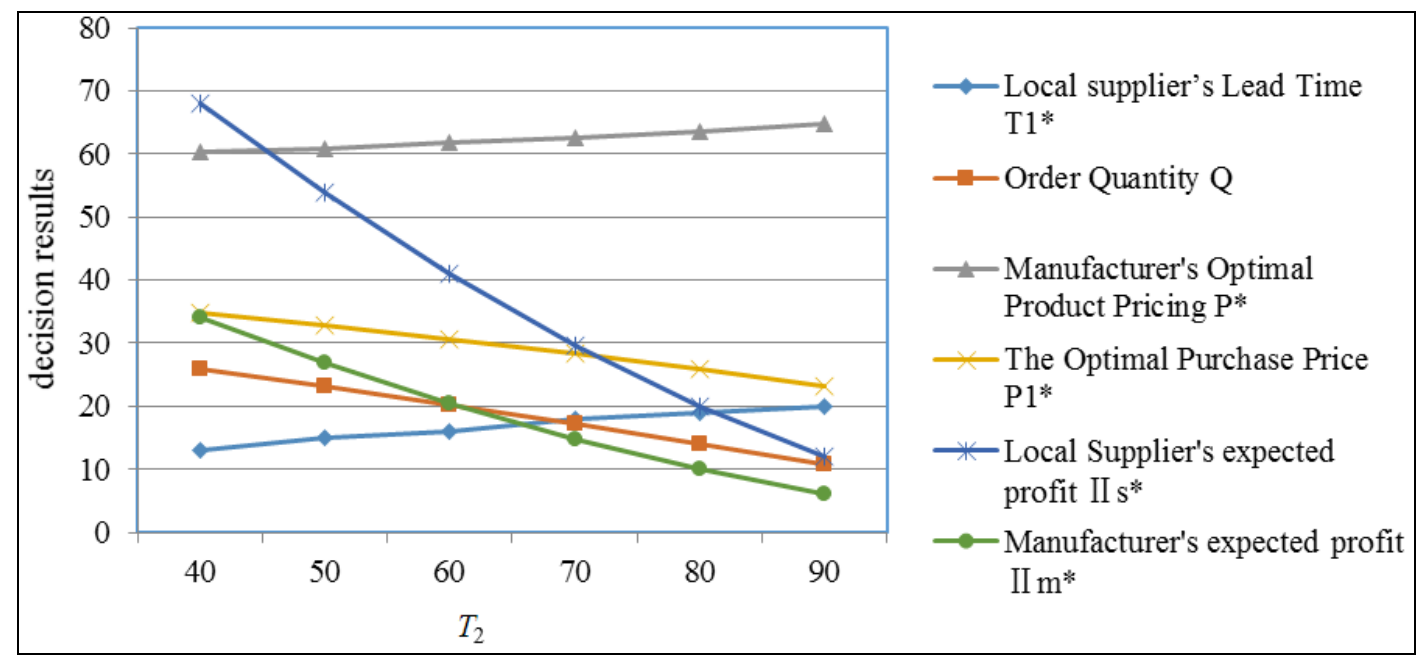

Figure 5: Trends of decision results under different delivery times $\left(T_{2}\right)$ of the overseas supplier. 
Table I: Results of supply chain decision under different delivery times of overseas supplier.

\begin{tabular}{|c|c|c|c|c|c|c|}
\hline Parameters & \multicolumn{4}{|c|}{ Decision variables } & \multicolumn{2}{c|}{ Supply chain performance } \\
\hline$T_{2}$ (day) & $T_{1}{ }^{*}$ (day) & $Q$ (piece) & $P^{*}(\$ /$ piece $)$ & $P_{1}{ }^{*}(\$ /$ piece $)$ & $\Pi_{s}^{*}(\$)$ & $\Pi^{*}{ }_{m}(\$)$ \\
\hline 40 & 13 & 260 & 603.5 & 349.3 & 68020 & 34010 \\
\hline 50 & 15 & 232 & 609 & 328.3 & 53780 & 26890 \\
\hline 60 & 16 & 202 & 617.5 & 306.3 & 41000 & 20500 \\
\hline 70 & 18 & 172 & 626.3 & 282.8 & 29700 & 14850 \\
\hline 80 & 19 & 141 & 636 & 258 & 20010 & 10000 \\
\hline 90 & 20 & 109 & 646.6 & 232.1 & 12080 & 6039 \\
\hline
\end{tabular}

The numerical results are as follows:

(1) A positive function relation exists between the delivery times of the local and overseas suppliers. For the given delivery time of the overseas supplier, a unique corresponding delivery time of the local supplier exists to make the two suppliers supply collaboratively.

(2) When the delivery time of the overseas supplier is extended, the delivery time of the local supplier should be extended accordingly in the optimization decision of the manufacturer to realize the collaborative supply.

(3) With the extension of the delivery time of the overseas supplier, the manufacturer needs to increase the product quotation for customers to maximize its own profit. Then, the demands and the optimal expected profit of the manufacturer will reduce consequently.

(4) The manufacturer will force down the purchasing price to transfer the income loss. The decreased amplitude of the profit of the local supplier with the extension of delivery time is high under the double pressures that the price and purchasing quantity drop simultaneously.

\subsection{Effect of the different delivery time sensitivities (v) of customers on supply chain decision results}

Great delivery time sensitivity coefficient indicates strong customer sensitivity to delivery time, thereby affecting the supply chain decision and the profits of both parties. The simulation interval of $v$ is set to 10-30 pieces/day according to the customer characteristics of the Aeron chair. Table II shows the effects of sensitivity coefficient on supply chain decision.

We can draw the changing trends of the supply chain decision results under different customer delivery time sensitivities according to the data in Table II, as shown in Fig. 6.

The numerical results are as follows:

(1) The delivery time, component-purchasing price, product demands, and product-selling price all decrease with an increase in customer delivery time sensitivity. The increase in sensitivity decreases the product demand rate. Consequently, the manufacturer will reduce the selling price and force down the purchasing price to stabilize the market demands and to maintain the maximum profit. The manufacturer will also cut down the delivery time of the local supplier to promote the response level.

(2) With an increase in customer delivery time sensitivity, the difficulty of meeting market demands will increase, whereas the optimal expected profit level of each party of supply chain will decrease. The supply chain should have a rapid response speed to meet the market demands. Suppliers should, thus, supply rapidly and collaboratively.

(3) For a group of given sensitivity coefficients and the delivery time parameters of the overseas supplier, a unique optimal strategy combination $\left(P^{*}, P_{1}{ }^{*}, T_{1}{ }^{*}\right)$ exists to make the supply chain performance optimal. Therefore, under the premise that the delivery condition of the overseas supplier is difficult to improve, the manufacturer should fully consider the time and price sensitivity to make a differentiated cooperation strategy with local suppliers. 
Li, Fan, Huang, Kwangseek: Collaborative Supply Model and Case Simulation in a Two- ...

Table II: Results of supply chain decision under different delivery time sensitivities.

\begin{tabular}{|c|c|c|c|c|c|c|c|}
\hline \multicolumn{2}{|c|}{ Parameters } & \multicolumn{4}{|c|}{ Decision variables } & \multicolumn{2}{|c|}{$\begin{array}{l}\text { Supply chain } \\
\text { performance }\end{array}$} \\
\hline$v$ (pieces/day) & $T_{2}$ (day) & $T_{1}^{*}$ (day) & $Q$ (piece) & $P_{1}^{*}(\$ /$ piece $)$ & $P^{*}(\$ /$ piece $)$ & $\Pi_{s}^{*}(\$)$ & $\Pi_{m}^{*}(\$)$ \\
\hline 10 & 40 & 13 & 260 & 349.3 & 603.5 & 68020 & 34010 \\
\hline 15 & 40 & 11 & 256 & 336.9 & 586.1 & 66040 & 33020 \\
\hline 20 & 40 & 10 & 255 & 329.1 & 573.1 & 65830 & 32710 \\
\hline 25 & 40 & 8 & 250 & 324.7 & 563.7 & 65430 & 32190 \\
\hline 30 & 40 & 7 & 248 & 303 & 557.1 & 606000 & 30530 \\
\hline 10 & 50 & 15 & 232 & 328.3 & 600.9 & 53780 & 26890 \\
\hline 15 & 50 & 13 & 225 & 313.9 & 588.1 & 50800 & 25400 \\
\hline 20 & 50 & 12 & 221 & 303.4 & 570.6 & 48950 & 24470 \\
\hline 25 & 50 & 11 & 218 & 295.9 & 556.3 & 47950 & 23970 \\
\hline 30 & 50 & 9 & 218 & 238.1 & 544.9 & 47620 & 23810 \\
\hline 10 & 60 & 16 & 202 & 306.3 & 617.5 & 41000 & 20500 \\
\hline 15 & 60 & 15 & 193 & 290.2 & 592.3 & 37630 & 18810 \\
\hline 20 & 60 & 13 & 187 & 277.6 & 571 & 35220 & 17610 \\
\hline 25 & 60 & 12 & 183 & 267.9 & 553 & 33540 & 16770 \\
\hline 30 & 60 & 11 & 180 & 260.4 & 537.7 & 32420 & 16210 \\
\hline 10 & 70 & 18 & 172 & 282.8 & 626.3 & 29700 & 14850 \\
\hline 15 & 70 & 16 & 162 & 265.4 & 598 & 26340 & 13170 \\
\hline 20 & 70 & 15 & 154 & 251.3 & 573.6 & 23820 & 11910 \\
\hline 25 & 70 & 14 & 148 & 239.8 & 552.5 & 21920 & 10960 \\
\hline 30 & 70 & 13 & 143 & 230.4 & 534 & 20500 & 10250 \\
\hline 10 & 80 & 19 & 141 & 258 & 636 & 20010 & 10000 \\
\hline 15 & 80 & 17 & 130 & 239.5 & 605.1 & 16950 & 8477 \\
\hline 20 & 80 & 16 & 121 & 224.2 & 578.1 & 14620 & 7311 \\
\hline 25 & 80 & 15 & 113 & 211.3 & 554.1 & 12830 & 6413 \\
\hline 30 & 80 & 14 & 107 & 200.5 & 532.9 & 11440 & 5716 \\
\hline 10 & 90 & 20 & 109 & 232.1 & 646.6 & 12080 & 6039 \\
\hline 15 & 90 & 18 & 97 & 212.7 & 613.4 & 9541 & 4771 \\
\hline 20 & 90 & 17 & 87 & 196.3 & 583.9 & 7628 & 3814 \\
\hline 25 & 90 & 16 & 78 & 182.3 & 557.6 & 6167 & 3084 \\
\hline 30 & 90 & 15 & 71 & 170.3 & 533.9 & 5046 & 2523 \\
\hline
\end{tabular}

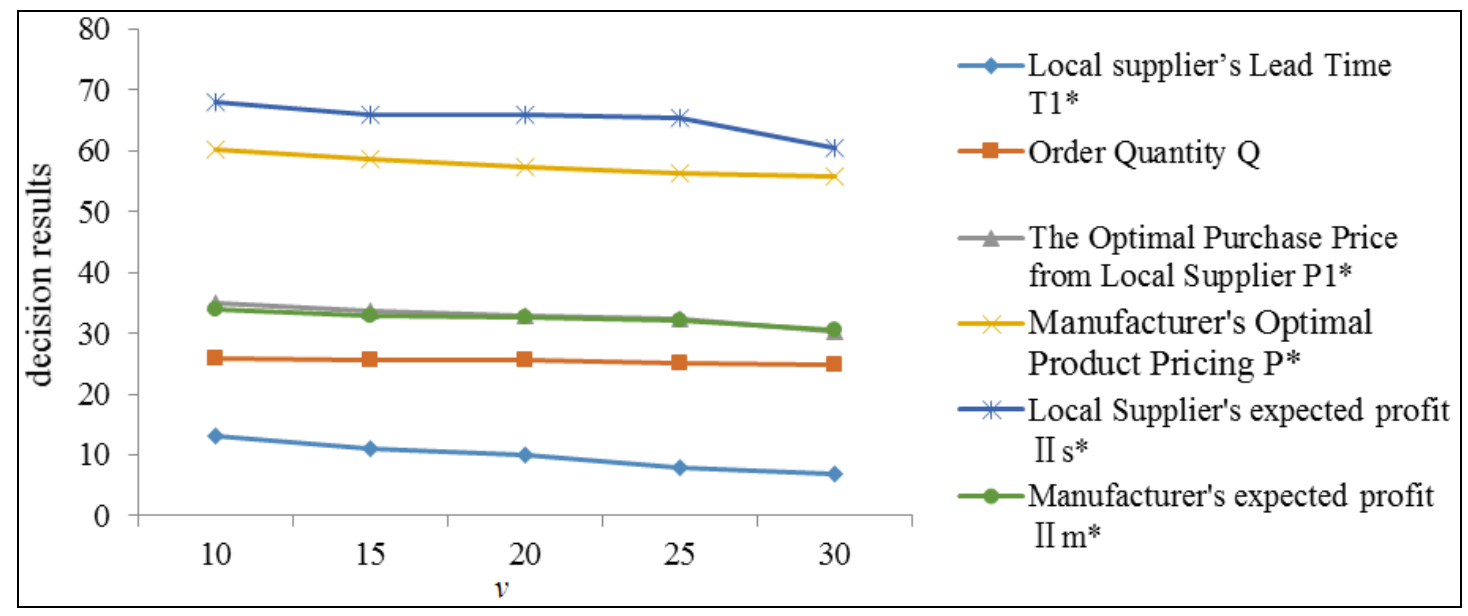

Figure 6: Trends of decision results under different delivery time sensitivities (v) (e.g., $\left.T_{2}=40\right)$. 


\section{CONCLUSIONS}

A collaborative supply model with a single manufacturer and multiple suppliers was established based on the CBA method with time constraints to study the collaborative supply strategy in time-price-sensitive ATO supply chain. The following conclusions were obtained:

(1) The collaborative supply between overseas and local suppliers is an important approach to improving the overall ATO supply chain performance and the benefits of each party in global purchasing and is also considered a challenge in supply chain management. The supply chain cooperation contract determined by model optimization can simultaneously improve the expected profits of the manufacturer and local suppliers.

(2) The functional relationships between supply chain profit and product price, component-purchasing price, and delivery time are given in the model. The results confirm that the Nash equilibrium solution $\left(P^{*}, P_{1}{ }^{*}, T_{1}{ }^{*}\right)$ of the supply chain can be derived in a decentralized decision-making mode. The supply strategy combination $\left(T_{1}^{*}, T_{2}\right)$ of the two types of suppliers is the collaborative supply strategy combination.

(3) The expected profits of both the manufacturer and the suppliers decrease with an increase in customer time sensitivity and the extension of delivery time. For any given sensitivity coefficient and the delivery time of the overseas supplier, a unique collaborative supply strategy combination is available to make the ATO system performance optimal. The supply chain cooperation contract between the manufacturer and the local suppliers can be designed based on this result.

The following are the caveats that apply to the present study. Only two types of suppliers were considered, and the result discussion mainly focused on time sensitivity analysis. The future research can be extended to additional types of suppliers to make the conclusions considerably close to practical application. In the result discussion, the double impacts of time sensitivity and price sensitivity can be considered. The adoption of vendor-managed inventory will bring systematic innovation to collaborative supply in the ATO system. The evaluation of implementation conditions and performance is also a direction for future research.

\section{ACKNOWLEDGEMENT}

The study was supported by the Youth Program of Humanities and Social Science Foundation of Ministry of Education of China (12YJC790099), the Key Youth Program of Zhejiang University Major Projects in Humanities and Social Science Research Plan (2013QN080), and the National Natural Science Foundation of China (71373244).

\section{REFERENCES}

[1] Ma, S. H.; Wang, F. S. (2006). Study on the decision mode of supply chain for time-sensitive and price-sensitive demand, Chinese Journal of Management Science, Vol. 14, No. 3, 13-19, doi:10.16381/j.cnki.issn1003-207x.2006.03.003

[2] Wemmerlöv, U. (1984). Assemble-to-order manufacturing: implications for materials management, Journal of Operations Management, Vol. 4, No. 4, 347-368, doi:10.1016/0272-6963(84)90021-4

[3] Du, X.; Jiao, J.; Tseng M. (2001). Understanding the architecture of product family for mass customization, Proceedings of 2001 World Congress on Mass Customization and Personalization, $1-12$

[4] Wei, Y.; Chen, F. Y.; Lee, M.; Yan, H.; Kong, K.; Ng, C. H. (2010). Divide and conquer: from MTO to ATO/MTO, A case study of an electronics manufacturer, Cheng, T. C. E; Choi, T.-M. (Eds.), Innovative Quick Response Programs in Logistics and Supply Chain Management, International Handbooks on Information Systems, Springer, Berlin, 331-354, doi:10.1007/978-3$\underline{\text { 642-04313-0_17 }}$ 
[5] Li, G.; Zhang, X.; Ma, S. H.; Wang, Z. H. (2012). Ordering optimization and coordination in supply chain assembly system under uncertain delivery conditions, Computer Integrated Manufacturing System, Vol. 18, No. 2, 369-380, doi:10.13196/j.cims.2012.02.147.lig.013

[6] Chandra, C.; Grabis, J. (2008). Inventory management with variable lead-time dependent procurement cost, Omega, Vol. 36, No. 5, 877-887, doi:10.1016/j.omega.2006.04.009

[7] Wang, C. X. (2009). Random yield and uncertain demand in decentralized supply chains under the traditional and VMI arrangements, International Journal of Production Research, Vol. 47, No. 7, 1955-1968, doi:10.1080/00207540701666220

[8] Gallien, J.; Wein, L. M. (2001). A simple and effective component procurement policy for stochastic assembly systems, Queueing Systems, Vol. 38, No. 2, 221-248, doi:10.1023/ A:1010914600116

[9] Fong, D. K. H.; Fu, H.; Li, Z. (2004). Efficiency in shortage reduction when using a more expensive common component, Computers \& Operations Research, Vol. 31, No. 1, 123-138, doi:10.1016/S0305-0548(02)00183-1

[10] Benjaafar, S.; ElHafsi, M. (2006). Production and inventory control of a single product assembleto-order system with multiple customer classes, Management Science, Vol. 52, No. 12, 18961912, doi: $10.1287 / \mathrm{mnsc} .1060 .0588$

[11] Gurnani, H.; Gerchak, Y. (2007). Coordination in decentralized assembly systems with uncertain component yields, European Journal of Operational Research, Vol. 176, No. 3, 1559-1576, doi:10.1016/j.ejor.2005.09.036

[12] Maddah, B.; Jaber, M. Y. (2008). Economic order quantity for items with imperfect quality: revisited, International Journal of Production Economics, Vol. 112, No. 2, 808-815, doi:10.1016/j.ijpe.2007.07.003

[13] Güler, M. G.; Bilgiç, T. (2009). On coordinating an assembly system under random yield and random demand, European Journal of Operational Research, Vol. 196, No. 1, 342-350, doi:10.1016/j.ejor.2008.03.002

[14] Feng, Y.; Ou, J.; Pang, Z. (2008). Optimal control of price and production in an assemble-toorder system, Operations Research Letters, Vol. 36, No. 4, 506-512, doi:10.1016/j.orl. 2008.01.012

[15] Li, G.; Ma, S. H.; Gao, T.; Wang, Z. H. (2011). A coordination model of two-suppliers and onemanufacturer under uncertain delivery, Journal of Industrial Engineering and Engineering Management, Vol. 25, No. 3, 91-99, doi:10.13587/j.cnki.jieem.2011.03.003

[16] Song, H. M.; Yang, H. (2009). Joint inventory decision with controllable lead time and productivity, Statistics \& Decision, Vol. 297, No. 21, 166-169, doi:10.13546/j.cnki.tjyjc. 2009.21.022

[17] Dan, B.; Li, Y. Y.; Huang, B. (2011). Mixed component replenishment policies for ATO supply chain under mass customization circumstance, Computer Integrated Manufacturing Systems, Vol. 17, No. 6, 1271-1278, doi:10.13196/j.cims.2011.06.153.danb.017

[18] Shanthikumar, J. G.; Sumita, U. (1988). Approximations for the time spent in a dynamic job shop with applications to due-date assignment, International Journal of Production Research, Vol. 26, No. 8, 1329-1352, doi:10.1080/00207548808947949

[19] Su, J. N.; Chen, J. H.; Liu, C. G. (2011). Coordination of time-varying price supply chain under uncertain response time, Systems Engineering - Theory \& Practice, Vol. 31, No. 3, 461-470 